\title{
7
}

\section{The Use of Magnetoencephalography to Evaluate Febrile Seizures and Epilepsy in Children}

\author{
A. Kotini ${ }^{1}$, A. Tsalkidis ${ }^{2}$, P. Anninos ${ }^{1}$ and A. Chatzimichael ${ }^{2}$ \\ ${ }^{1}$ Lab of Medical Physics and \\ 2Dept of Paediatrics, Medical School Democritus University of Thrace, Alex/polis,
}

Greece

\section{Introduction}

The International League Against Epilepsy (ILAE) defined the febrile seizures as seizures occurring in childhood after one month of age, associated with a febrile illness not caused by an infection of the central nervous system, without previous neonatal seizures or a previous unprovoked seizure and not meeting the criteria for other acute symptomatic seizure (Østergaard, 2009). There is no evidence that electroencephalography (EEG) abnormalities help in the prediction of the development of subsequent epilepsy and are of limited value (American Academy of Pediatrics, 1996). Computed tomography (CT) and magnetic resonance imaging (MRI) is not indicated in children with simple febrile seizures, but may be useful in cases with prolonged or focal febrile seizures in order to reveal subtle underlying neurological diseases (Shinnar and Glauser, 2002).

The neuromagnetic field recordable outside of the head is a selective reflection of intracellular currents flowing in the apical dendrites of pyramidal cells parallel to the skull surface. The magnetic field generated by a single neuron is almost negligible. When several thousands of nearby cells are synchronously active, the summated extracranial magnetic field typically achieves a magnitude of a few hundred femto-Tesla $\left(1 \mathrm{fT}=10^{-15}\right)$ where the strongest neuromagnetic signals like those associated with epileptic spikes are a few thousands femto-Tesla (Rose et al., 1987, Anninos et al., 1987; 1989a,b; 1991;1997; 1999a,b; 2000a-c; 2003; 2010;Anastasiadis et al., 1997, Kotini et al., 2007a-c). The magnetic activity of the brain is produced by cellular micro-currents, which emerge from ionic movements, due to the dynamical variations of the membrane potentials (Anninos and Raman, 1975; Anninos 1973).

The SQUID (Superconductive Quantum Interference Device) has the ability to detect magnetic fields of the order of 10-12T which are much smaller than the magnetic fields of the earth which are $5 \times 10-5 \mathrm{~T}$. The SQUID is based on the Josephson effect of superconductivity (Josephson, 1962). Using multi-channel recordings the topography of the magnetic field can be recorded above the scalp with a temporal resolution of less than one millisecond (Braun, 2007). The signal measured by each channel of the SQUID is a time varying waveform voltage that reflects local changes in the magnetic flux as a function of time. This signal is called magnetoencephalography (MEG) if we measured the brain emitted magnetic fields 
and it is very similar to the EEG if we measured the brain emitted electric fields. MEG is a non-invasive method for the study of electro-magnetic brain activity.

The major advantage of MEG over EEG, is that MEG has higher localization accuracy. This is due to the fact, that the different structures of the head influence the magnetic fields less than the volume current flow, that causes the EEG. MEG provides a high spatial density of recording points, which is difficult to obtain with EEG. The magnetic fields, are less distorted than electrical fields, because of the blurring effect of the skull, which acts as a low-pass filter for electrical potentials, providing, in this way, better conditions for the recording of fast activity. Moreover, inaccuracies in estimating the conductivities of the skull and other tissues of the head affect much more the interpretation of electrical than magnetic sources (Sobel et al., 2000; Wilson et al. 2007; Ramantani et al.,2006; RamachandranNai et al., 2007; Anninos et al., 2010; Kylliäinen et al.,2006; Elger et al., 1989) .

The MEG offers functional mapping information and measurement of brain activity in real time, unlike CT, MRI and functional magnetic resonance imaging (fMRI) which provide anatomical, structural and metabolic information. With the MEG the brain is seen in 'action' rather than viewed as a still image. Finally, the MEG has far more superior ability to resolve millisecond temporal activity associated with the processing of information which is the main task of the brain. Thus, both normal spontaneous rhythms and pathological activities are readily identified in MEG waveforms as we do with the EEG waveforms. Whereas, MEG signals reflect current flow in the apical dentrites of pyramidal cells oriented tangential to the skull surface, EEG signals reflect both tangential and radial activities (Williamson and Kaufman, 1987; Cohen D and Cuffin, 1991; Lopes da Silva and Van Rotterdam,1987; Rose and Ducla-Soares, 1990; Hamalainen, 1993; Makela, 1996). For all of the above reasons we preferred the use of MEG for the evaluation of seizures.

In this study we investigated the possibility of any epileptic behavior caused by febrile seizures in 4 young sisters, by means of MEG. We utilized MEG to measure epileptic behavior because EEG abnormalities were not useful for the prediction of the development of subsequent epilepsy.

\section{Methods}

Four young sisters within the age range of 2 - 5 years were referred to our Lab by the Pediatric Department of our University General Hospital in order to be examined with MEG. There were no EEG, CT and MRI examinations in the patients' records. Informed consent for the methodology and the aim of the study was obtained from their parents prior to the procedure.

The MEG recordings were carried out in a magnetically shielded room with a whole head 122-channel-biomagnetometer (Neuromag-122, Helsinki, Finland) (Anninos et al., 2010; 2006; Kotini et al., 2010; 2008; 2005;2004; 2002; Tonoike et al., 1998; Antoniou et al., 2004) (Figure 1). All studies performed precisely 10 days after fever subsided for the purpose of comparison. The time duration of each MEG measurement was $3 \mathrm{~min}$.

There was adequate head coverage for all children by the whole head helmet-shaped dewar. The MEG sensors were adjacent to the scalps. The sensors were consisted of rectangular pairs of planar-type gradiometers aligned in a helmet-shaped dewar vessel, into which the patient's head was inserted during the measurement. The pick-up-coils of the device are shaped like figure-of-eights to make them 'near-sighted', i.e. sensitive to sources in the brain, but insensitive to ambient noise fields. The device employs planar gradiometers that 
record at each of the 61 measurement sites the magnetic field component normal to the helmet-shaped dewar bottom surface.
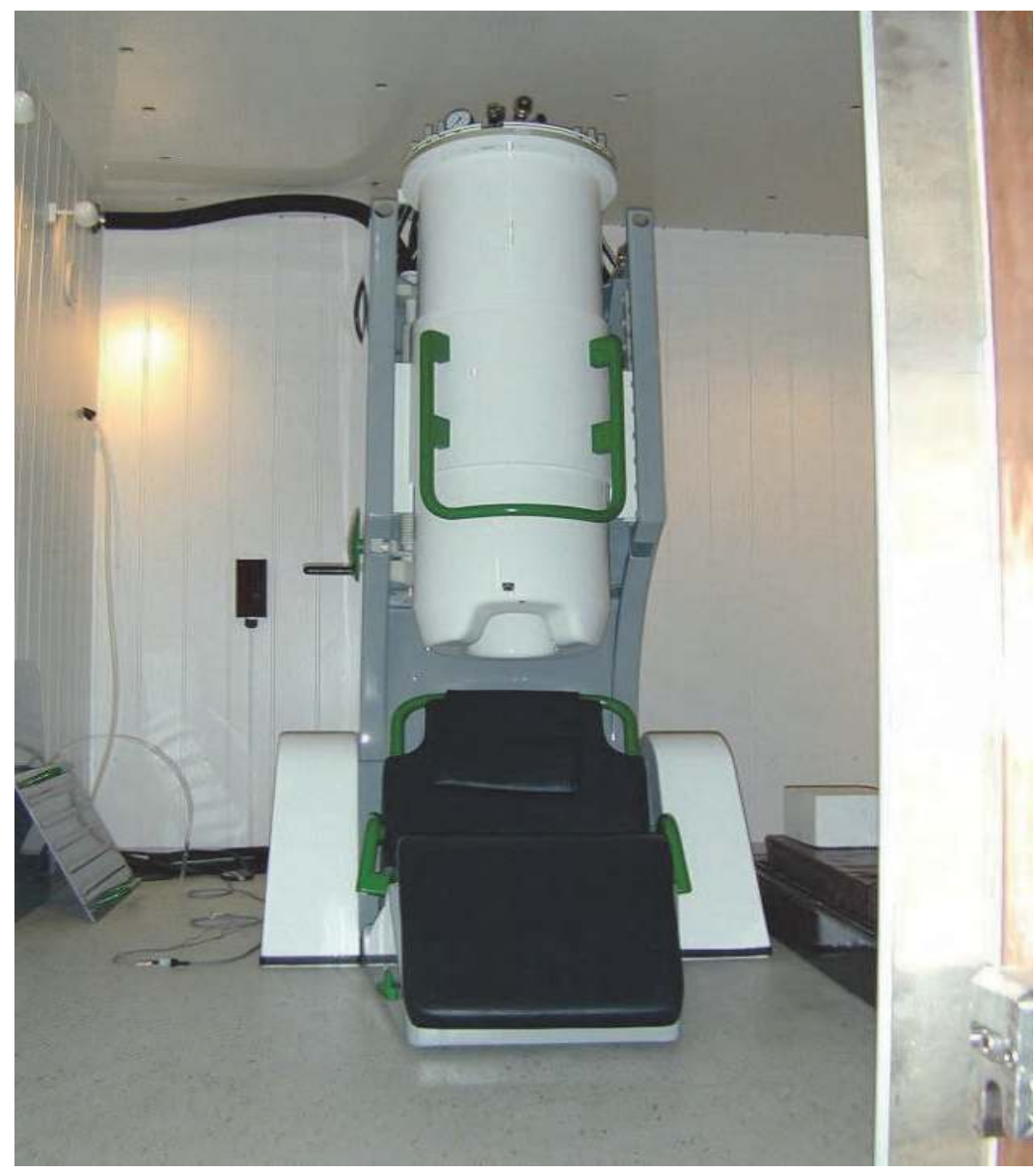

Fig. 1. The 122-channel-biomagnetometer

All MEG data were inspected carefully off-line for movement artifacts which were cut off from the data trace. The data were bandpass filtered between 0.03 and $130 \mathrm{~Hz}$ and sampled at $400 \mathrm{~Hz}$. During off-line data analysis, we used a low-pass filter at $40 \mathrm{~Hz}$ and high-pass at 2-8 $\mathrm{Hz}$ to extract the spike component from the slower background activity.

When a clear dipole pattern was seen in the magnetic field distribution around the spike peak, the single equivalent current dipole (ECD) model was fitted in the patient's spherical head model to the recorded signals. We defined acceptable ECDs as those with a goodnessof-fit to the model of $>80 \%$ and with ECD strength between 100 and 400 nAm (nano Ampere metre).

For the transformation of the ECD locations, the following coordinate system was used: $x-$ axis perpendicular to the other two axes through the anterior commissure, $y$-axis passing 
through the anterior and posterior commissure, and z-axis perpendicular to the $y$-axis through the anterior commissure at the middle plane of the brain.

Normal subjects of similar age who served as controls didn't show ECDs in their MEGs because normal controls did not have any spike activity on which to fit the data. The same sort of analyses was performed on the normal control data.

\subsection{Results}

Table 1 exhibits the clinical characteristics of each child. After the MEG signals were recorded, an ECD model was estimated at each time point, within the encompassing signal segment, using a single dipole model.

Two out of the 4 children shown ECD dipoles located at the right - temporal areas (Figs.2,3, child No 1,3), as active regions responsible for febrile seizures. These children were scheduled for future clinical examination with EEG due to the high number of events of febrile seizures (Table 1).

The children had a family history of febrile seizures. Their uncle (fathers' brother) had one event of febrile seizures and occurrence of epilepsy seizures during his life.

Figures 4, 5 exhibit the scalp MEG distribution for the children No.3,4 respectively. There are no ECD dipoles.

\begin{tabular}{|l|l|l|l|l|l|l|}
\hline $\begin{array}{l}\text { No of } \\
\text { cases }\end{array}$ & Age & Sex & $\begin{array}{c}\text { No of } \\
\text { events of } \\
\text { febrile } \\
\text { seizures }\end{array}$ & \multicolumn{1}{|c|}{ Type of seizures } & $\begin{array}{l}\text { Duration of } \\
\text { seizures }\end{array}$ & MEG \\
\hline 1 & 5 years & F & 3 & $\begin{array}{l}\text { Generalized tonic }- \\
\text { clonic } \\
\text { Simple febrile seizures }\end{array}$ & $1-2$ min & ECD \\
\hline 2 & 4 years & F & 1 & $\begin{array}{l}\text { Generalized tonic }- \\
\text { clonic } \\
\text { Simple febrile seizures }\end{array}$ & $1-2$ min & N \\
\hline 3 & 2.5 years & F & 4 & $\begin{array}{l}\text { Generalized tonic }- \\
\text { clonic } \\
\text { Simple febrile seizures }\end{array}$ & $1-2$ min & ECD \\
\hline 4 & 15 months & F & 1 & $\begin{array}{l}\text { Generalized tonic }- \\
\text { clonic } \\
\text { Simple febrile seizures }\end{array}$ & $1-2$ min & N \\
\hline
\end{tabular}

Table 1. The clinical characteristics of each child. F: Female; N: Normal, ECD: Equivalent Current Dipole

\section{Conclusion}

The most prevalent pathology following febrile seizures is a recurrence, which occurs in about one-third of the cases. The most reliable risk factors for the reappearance reported are the onset of first febrile seizures at less than 18 months of age and the family history of febrile seizures. Two other specific risk factors for reappearance are the peak temperature and the duration of the fever period prior to the seizure. The higher the peak temperature, the lower is the risk of recurrence and, the shorter the fever period before seizure, the higher 


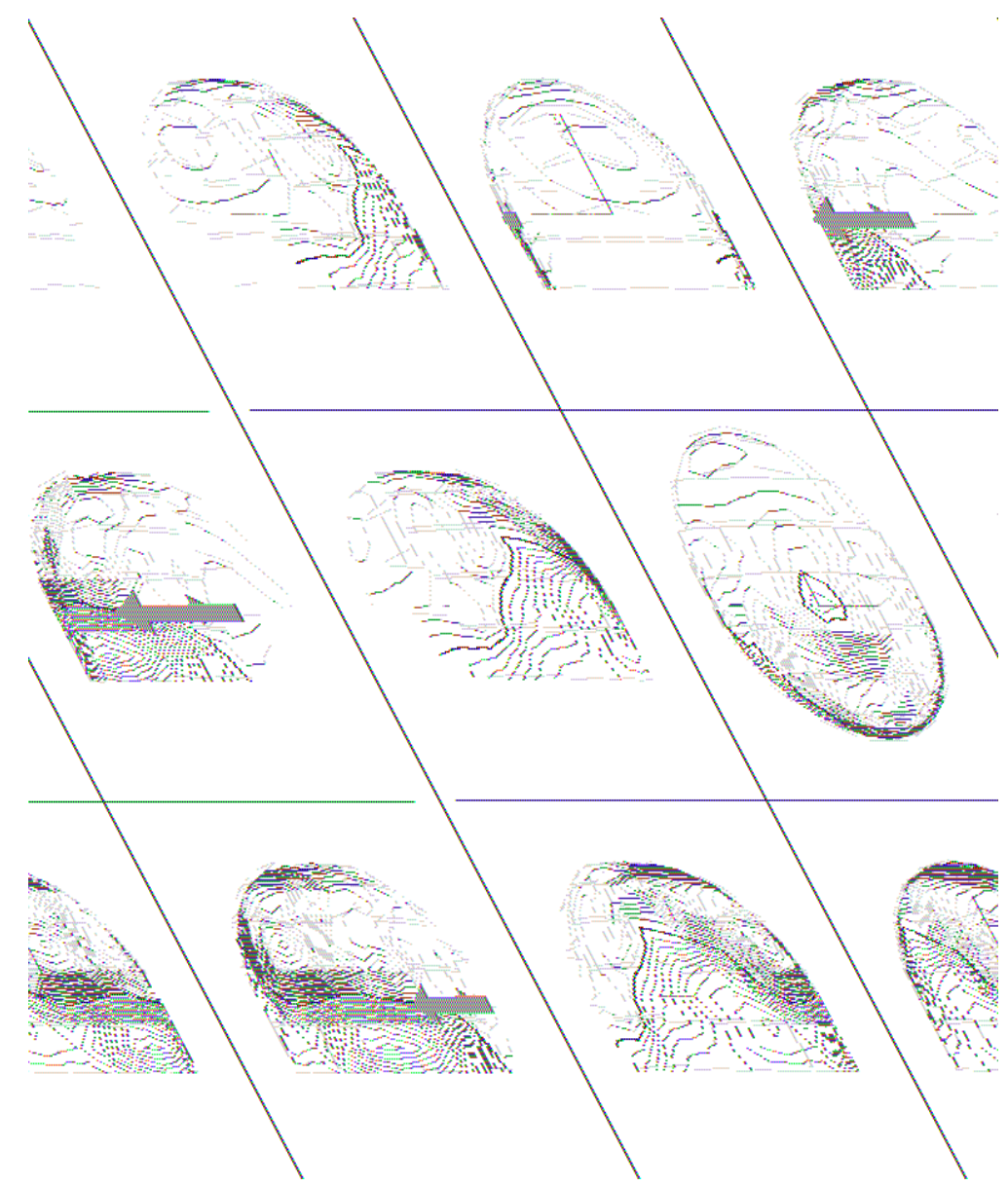

Fig. 2. The scalp MEG distribution and the ECD dipole indicated by the arrow in the child No.1 (Table 1). The coordinates are : $x$ (left/right), y (anterior/posterior), and $\mathrm{z}$ (superior/inferior)

is the risk for recurrence. Furthermore fearing new seizures, the parents are faced with a concern of their child's chance of developing epilepsy or mental retardation (Østergaard, 2009; Berg et al., 1997).

There are only three reports in the literature investigating febrile seizures with MEG. Mayanagi et al. (1996) studied the clinical features of mesial temporal lobe epilepsy in 24 cases. A history of febrile convulsion, particularly in the form of status epilepticus, seemed to be a prognostic factor. For presurgical evaluation, EEG, MRI, MEG and single photon emission computed tomography (SPECT) were important tests.

Mohamed et al. (2007) referred to a previously healthy 10-year-old boy who developed generalized convulsive status epilepticus following a mild febrile illness. Ictal and interictal MEG demonstrated dipole sources projecting from the right mesial temporal region. 


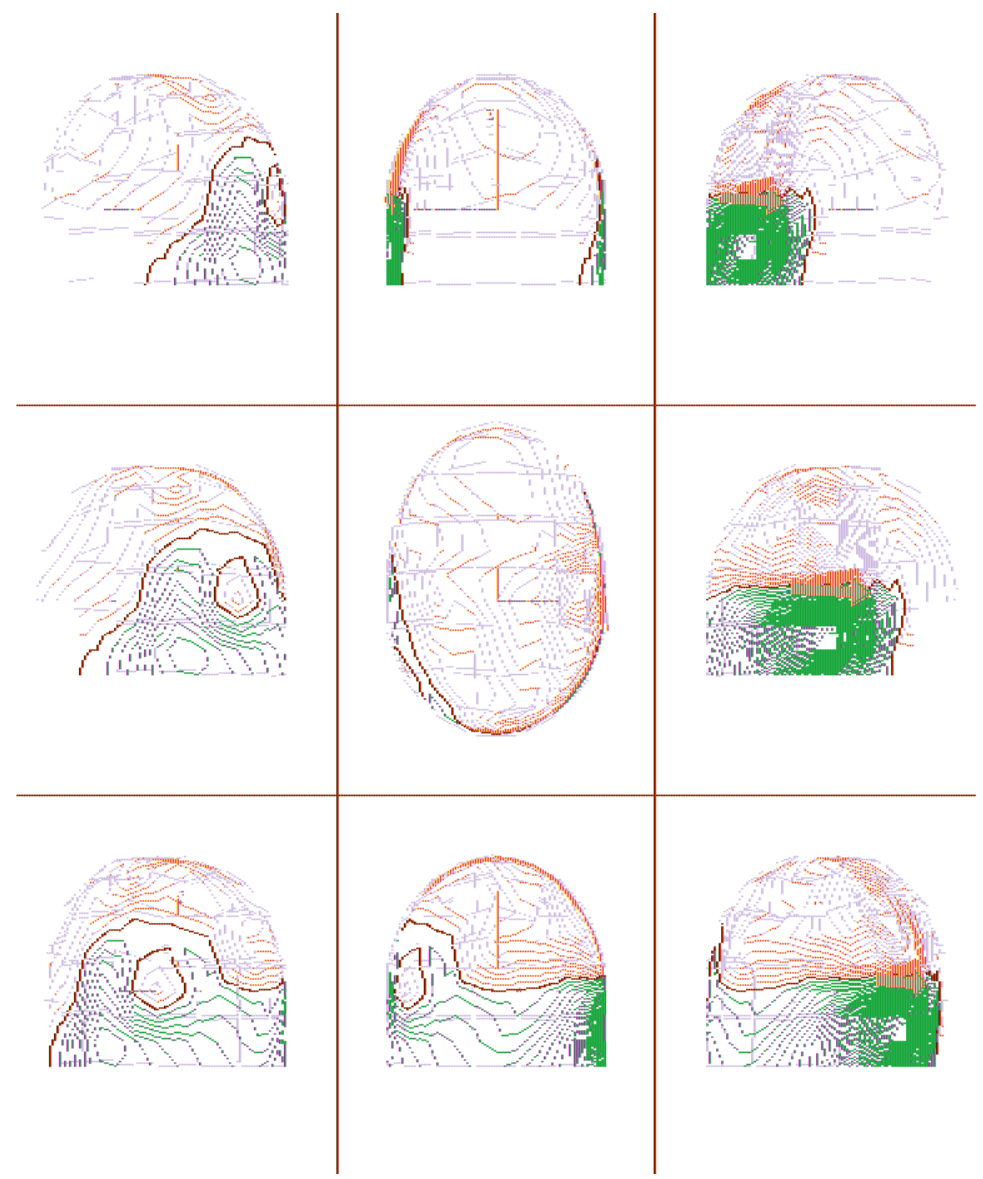

Fig. 3. The scalp MEG distribution and the ECD dipole indicated by the arrow in the child No.3 (Table 1). The coordinates are : $x$ (left/right), y (anterior/posterior), and $\mathrm{z}$ (superior/inferior)

Diffusion-weighted imaging showed restricted diffusion involving the right hippocampus. Right anterior temporal lobectomy resulted in cessation of status epilepticus.

Anninos et al. (2010) studied 15 children within the age range of 2 - 7 years who experienced febrile seizures. Eight children showed ECDs located at the left-temporal, right-temporal, occipital, and frontal lobe, as active regions responsible for febrile seizures. They assumed that the interictal epileptiform discharges are a consequence of febrile seizures.

The most simple and widely used model that can explain a certain MEG surface map is the ECD, which assumes that the magnetic fields recorded at the surface can be accounted by a dipolar source. This model arises from the physiological observation that the main neuronal sources of MEG activity consist of palisades of cortical pyramidal cells, with elongated apical dendrites oriented perpendicularly to the cortical surface. The estimation of a dipole model is reasonable only if the magnetic field on the surface has focal characteristics(Sobel et al., 2000; RamachandranNair et al. 2007; Ramantani et al., 2006; Wilson et al., 2007; 


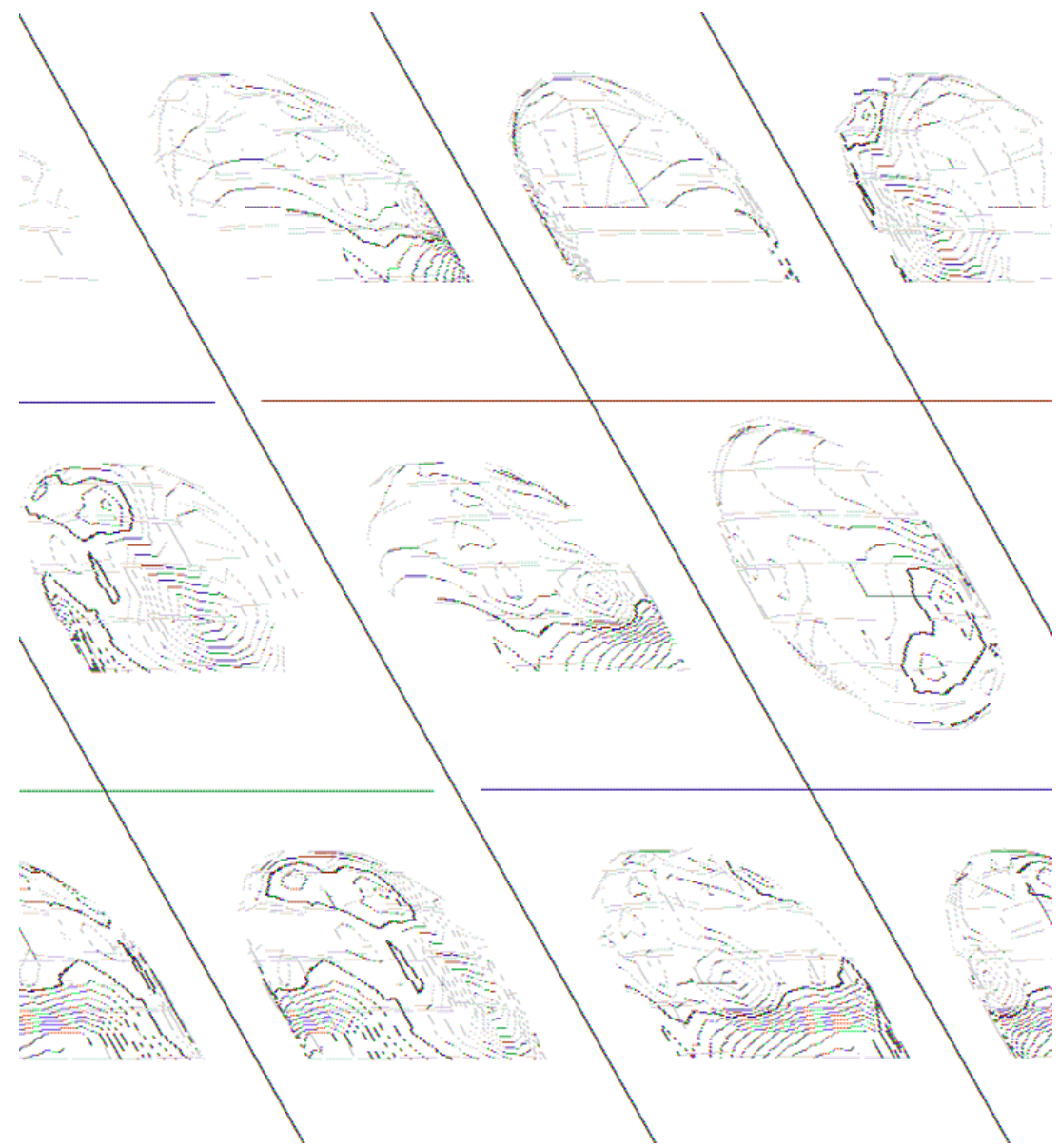

Fig. 4. The scalp MEG distribution in the child No2 (Table 1). The coordinates are : $x$ (left/right), y (anterior/posterior), and z (superior/inferior)

Scheler et al. 2007; Papanicolaou et al., 2006; Wu et al., 2006; Chuang et al., 2006). This model allows characterization of the source of neuronal activity in the brain and is useful in focal epilepsies, in which small areas of brain tissue trigger the seizure and are important in obtaining a good spatiotemporal localization of the foci. However, MEG might be helpful in more complex epileptic patterns (generalized epilepsy).

We defined acceptable ECDs as those with a goodness of fit to the model of $>80 \%$. Standard ECD analysis defines the spatial extent of an epileptogenic zone when reliable ECD localizations are gathered to form a single cluster (Oishi et al., 2006; Iida et al.,2005). One single cluster of MEG spike sources can indicate the primary epileptogenic zone for complete resection and seizure control. Multiple clusters indicate complex and extensive epileptogenic zones and necessitate intracranial EEG monitoring. MEG is a technique for measuring the magnetic fields associated mainly with intracellular currents, while the EEG measures mainly extracellular field potentials. Intracellular currents are well modeled by the ECD model. 


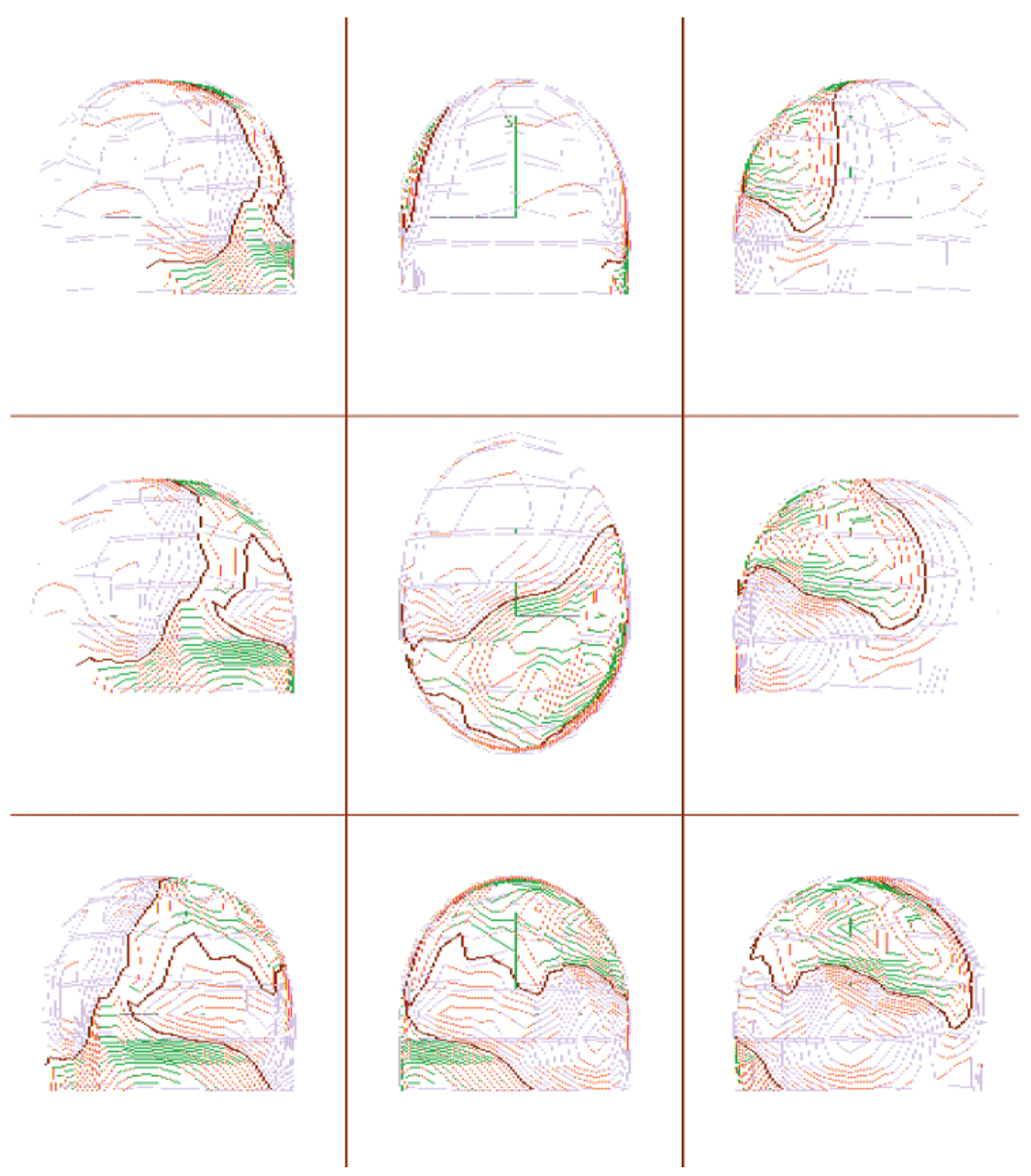

Fig. 5. The scalp MEG distribution in the child No.4 (Table 1). The coordinates are : $x$ (left/right), y (anterior/posterior), and z (superior/inferior)

In our study, 2 out of 4 children were positive to ECDs, whereas the rest were negative. This fact depends on the activity of the patients' brain during the MEG measurements. If exhibits epileptic behavior, then we will observe ECDs, otherwise we would not. Neuroimaging studies are not necessary in children with simple febrile seizures. EEG's have been found to have limited value( Jones and Jacobsen, 2007). Abnormalities on EEG do not predict the occurrence of future seizures or the subsequent development of epilepsy. (Kuturec et al., 1997; Joshi et al., 2005). It is well known that EEG is an unhelpful diagnostic procedure and we use it only when we want to distinguish "febrile convulsions" from convulsions with fever (Panayiotopoulos, 2002; Püst, 2004; Chung et al., 2006).

Time domain analysis of neuromagnetic data give information about the underlying neuronal generators and especially is appropriate for transient behavior. The utility of the ECD algorithm depends on the goodness of fit between the structure of the sources in the 
model and the neuronal sources. Frequency domain localization of ECD sources is useful if the underlying neuronal generators are differentiated harmonic content and spatial distribution. The existence of such sources has been demonstrated by the determination of ECD components of activity with both a sharp spectral peak and localized source volume. Both frequency and time domain analysis may be applied to the same epoch of time. The coincident occurrence of spike activity localization in the time domain and slow activity localization in the frequency domain may be an interesting tool for localization of epileptic activity. The separation of a complex set of sources underlying spontaneous activity into distinct components is an initial step in determining the functional significance of spontaneous activity

Children with febrile seizures have a six-fold excess (3\%) of subsequent afebrile seizures and epilepsy than controls. The risk is $2 \%$ after a simple and $5-10 \%$ after a complex febrile seizure. We tried to find a method that can supply us some prognostic indicators for possible epileptic behavior in children who experienced febrile seizures and have a family history of them. We assume that one of these prognostic indicators might be the existence of epileptiform discharges modeled by ECDs. Of course, further investigation is needed in order to assess the exact role of the ECDs and the occurrence of epilepsy in young children with a family history of febrile seizures.

\section{Abbreviations}

(ILAE) International League Against Epilepsy

(EEG) Electroencephalography

(CT) Computed tomography

(MRI) Magnetic resonance imaging

(SQUID) Superconductive Quantum Interference Device

(MEG) Magnetoencephalography

(fMRI) Functional magnetic resonance imaging

(SPECT) Single photon emission computed tomography

(ECD) Equivalent current dipole

\section{References}

American Academy of Pediatrics . Provisional committee on quality improvement: practice parameter: the neurodiagnostic evaluation of the child with a simple febrile seizure. Pediatrics. 1996; 97: 769-75

Anastasiasis P, Anninos PA, Diamantopoulos P, Sivridis E. Fetal magnetoencephalographic mapping in normal and preeclamptic pregnancies. J Obstet Gynaecol. 17(2), 1997, pp. 123-126.

Anninos P, Adamopoulos A, Kotini A, Tsagas N. Nonlinear analysis of brain activity in magnetic influenced Parkinson patients. Brain Topogr., 2000a, 13 (2) : 135-44.

Anninos P, Kotini A, Tsalkidis A, Dipla V, Chatzimichael A . MEG evaluation of febrile seizures in young children. J Child Neurol. 2010; 25:61-6

Anninos P.A., Anastasiadis P. \& Kotini A. : Nonlinear analysis of biomagnetic signals recorded from the umbilical artery in normal and pre-eclamptic pregnancies. Eur J Obstet Gynecol Reprod Biol 85 (1999a), 159 
Anninos P.A., Kotini A., Koutlaki N., Adamopoulos A., Galazios G. \& Anastasiadis P. : Differential Diagnosis of Breast Lesions by use of Biomagnetic Activity and NonLinear Analysis. Eur. J Gynaecol Oncol 21 (2000b) 591

Anninos PA, Adamopoulos A, Kotini A, Tsagas N. Nonlinear analysis of brain activity in magnetic influenced Parkinson patients. Brain Topography 2000c;13(2):135-144.

Anninos PA, and Raman S. Derivation of a mathematical equation for the EEG and the general solution within the brain and in space. Int. J. Theor. Phys. 12, 1975, pp. 1-9

Anninos PA, Anogianakis G, Lehnertz K,Pantev C, and Hoke M. Biomagnetic measurements using SQUID. Int. J.Neurosci. 37 :149-168(1987).

Anninos PA, Jacobson JI, Tsagas N, Adamopoulos A. Spatiotemporal stationarity of epileptic focal activity evaluated by analyzing magnetoencephalographic (MEG) data and the theoretical implications. Panminerva Med 1997;39:189-201.

Anninos PA, Kotini A, Adamopoulos A, Tsagas N. Magnetic stimulation can modulate seizures in epileptic patients. Brain Topography 2003;16(1):57-64

Anninos PA, Tsagas N, Jacobson, JI and Kotini A. The biological effects of magnetic stimulation in epileptic patients. Pannminerva Med. 41,1999b, pp.207-215

Anninos PA, Tsagas N, Sandyk R and Derpapas K. Magnetic stimulation in the treatment of partial seizures. Int. J. Neurosc. 60,1991, pp.141-171

Anninos, P.A. and Tsagas, N. Localization and cure of epileptic foci with the use of MEG measurements. Int. J. Neurosci., 1989a, 46: 235-242.

Anninos, P.A. Electromagnetic fields generated from neuronal activity TIT. Journal of Life Science 3, 1973, pp. 15

Anninos, P.A., Tsagas, N. and Adamopoulos, A. A brain model theory for epilepsy and the mechanism of treatment with experimental verification using SQUID measurements. In: R.M. Cotterill (Ed.), Models of Brain Function. New York Cambridge University Press, 1989b: 405-421.

Antoniou PE, Anninos PA, Piperidou H, Adamopoulos A, Kotini A, Koukourakis MI, Sivridis E. Non linear analysis of magnetoencephalographic signals as a tool for assessing malignant lesions of the brain: first results. Brain Topogr. 2004;17:117-23

Berg AT, Shinnar S, Darefsky AS, Holford TR, Shapiro ED, Salomon ME, Crain EF, Hauser AW . Predictors of recurrent febrile seizures. Arch Pediatr Adolesc Med. 1997; 151: 371-8

Braun C . Magnetoencephalography: a method for the study of brain function in neurosurgery. Z Med Phys. 2007;17:280-7

Chuang NA, Otsubo H, Pang EW, Chuang SH. Pediatric magnetoencephalography and magnetic source imaging. Neuroimaging Clin N Am. 16(1), 2006, pp.193-210.

Chung B, Wat LC, Wong V. Febrile seizures in southern Chinese children: incidence and recurrence. Pediatric Neurol. 34,2006, pp.121-126

Cohen D and Cuffin BD. EEG versus MEG localization accuracy:theory and experiment. Brain Topogr.4,95-103(1991).

Elger CE, Hoke M, Lehnertz K., et al. Mapping of MEG amplitude spectra: Its significance for the diagnosis of focal epilepsy. In: Maurer K, editor. Topographic brain mapping of EEG and evoked potentials. Berlin: Springer Verlag, 1989, 565-70.

Hamalainen M, Hari R, Ilmoniemi R, Knuutila J and Lounasmaa O. Magnetoencephalography-theory, instrumentation and applications to noninvasive studies of the working human brain. Rev. Mod. Phys 65: 1-93(1993). 
Iida K, Otsubo H, Matsumoto Y, Ochi A, Oishi M, Holowka S, Pang E, Elliott I, Weiss SK, Chuang SH, Snead OC 3rd, Rutka JT . Characterizing magnetic spike sources by using magnetoencephalography-guided neuronavigation in epilepsy surgery in pediatric patients. J Neurosurg.2005; 102(Suppl 2):187-96

ILAE. Guidelines for epidemiologic studies on epilepsy.Epilepsia. 34(4):1993, pp. 592-596.

Jones T, Jacobsen SJ. Childhood Febrile Seizures: Overview and Implications. Int J Med Sci. 2007; 4(2): 110-114

Josephson BD. Possible effects in superconductivity tunneling. Phys. Lett.1, 1962, pp 252-256

Joshi C, Wawrykow T, Patrick J, Prasad A. Do clinical variables predict an abnormal EEG in patients with complex febrile seizures? Seizure. 2005;14:429-34

Kotini A, Anninos P, Adamopoulos A, Prassopoulos P. Low Frequency MEG Activity and MRI Evaluation in Parkinson's Disease. Brain Topogr 2005; 18:59-63

Kotini A, Anninos P, Tamiolakis D. MEG mapping in multiple sclerosis patients. Eura Medicophys 2007a; 43:345-8

Kotini A, Anastasiadis AN, .Koutlaki N, .Tamiolakis D, Anninos P, Anastasiadis P. Biomagnetism in Perinatal Medicine. Our experience in Greece. Clin Exp Obstet Gynaecol 2007b;34:42-6

Kotini A, Anninos P, Tamiolakis D, Prassopoulos P . Differentiation of MEG activity in multiple sclerosis patients with the use of nonlinear analysis. J Integr Neurosci. 2007c;6:233-40

Kotini A, Anninos P. Detection of non-linearity in schizophrenic patients using magnetoencephalography. Brain Topogr. 2002;15:107-13

Kotini A, Camposano S, Hara K, Salat D, Cole A, Stufflebeam S, Halgren E. Cortical thickness in a case of Congenital Unilateral Perisylvian Syndrome. Neurol Clin Neurophysiol 2004;4:1-4

Kotini A, Mavraki E, Anninos P, Piperidou H, Prassopoulos P . Meg evaluation of epileptic activity in the time and frequency domain. J Integr Neurosci. 2008;7:463-80

Kotini A, Mavraki E, Anninos P, Piperidou H, Prassopoulos P. Magnetoencephalographic Findings in Two Cases of Juvenile Myoclonus Epilepsy. Brain Topogr. 2010; 23:41-5

Kuturec M, Emoto SE, Sofijanov N, et al. Febrile seizures: is the EEG a useful predictor of recurrences? Clin.Pediatr.(Phila). 1997;36:31-6

Kylliäinen A, Braeutigam S, Hietanen JK, et al. Face and gaze processing in normally developing children: a magnetoencephalographic study. Eur J Neurosci. 2006 ;23:801-10

Lopes da Silva F and Van Rotterdam A. Biophysical aspects of EEG and magnetoencephalogram generation. In: Niedermeyer E, Lopes da Silva F (Eds). Electroencephalography. Baltimore, Munich: Urban\& Schwarzenberg ,29-41(1987).

Makela JP. Neurological application of MEG. Electroencephalogr. Clin. Neurophysiol. Supp. Review 47: 343-355(1996).

Mayanagi Y, Watanabe E, Kaneko Y. Mesial temporal lobe epilepsy: clinical features and seizure mechanism. Epilepsia. 1996; 37 (Suppl 3):57-60

Mohamed IS, Otsubo H, Imai K, Shroff M, Sharma R, Chuang SH, Donner E, Drake J, Snead OC 3rd .Surgical treatment for acute symptomatic refractory status epilepticus: a case report. J Child Neurol. 2007; 22:435-9 
Oishi M, Kameyama S, Masuda H, Tohyama J, Kanazawa O, Sasagawa M, Otsubo H . Single and multiple clusters of magnetoencephalographic dipoles in neocortical epilepsy: significance in characterizing the epileptogenic zone. Epilepsia. 2006;47:355-64

Østergaard JR .Febrile seizures. Acta Paediatr. 2009; 98:771-3

Panayiotopoulos CP. A clinical guide to epileptic syndromes and their treatments 2002; 3:5052

Papanicolaou AC, Pazo-Alvarez P, Castillo EM, et al. Functional neuroimaging with MEG: normative language profiles. Neuroimage. 33(1), 2006, pp.326-342.

Püst B. Febrile seizures: an update. Kinderkankenschwester 2004;23:328-31 (Review)

Ramachandran Nair R, Otsubo H, Shroff MM, et al. MEG predicts outcome following surgery for intractable epilepsy in children with normal or nonfocal MRI findings. Epilepsia. 48(1), 2007, pp.149-157.

Ramantani G, Boor R, Paetau R, et al. MEG versus EEG: influence of background activity on interictal spike detection. J Clin Neurophysiol. 23(6), 2006, pp.498-508.

Rose DF and Ducla-Soares R. Comparison of electroencephalography and magnetoencephalography. In: Sato S (Ed.),Magnetoencephalography. New York: Raven press,33-37(1990).

Rose DF, Smith PD and Sato S. Magnetoencephalography and epilepsy research. Science 238, 1987, pp. 329-335.

Scheler G, Fischer MJ, Genow A, et al. Spatial relationship of source localizations in patients with focal epilepsy: comparison of MEG and EEG with a three spherical shells and a boundary element volume conductor model. Hum Brain Mapp. 28(4), 2007, pp.315-322.

Shinnar S, Glauser TA . Febrile seizures. J Child Neurol. 2002;17: S44-S52

Sobel DF, Aung M, Otsubo H, Smith MC. Magnetoencephalography in Children with Landau-Kleffner Syndrome and Acquired Epileptic Aphasia. AJNR Am J Neuroradiol. 2000; 21:301-307

Tonoike M, Yamaguchi M, Kaetsu I, Kida H, Seo R, Koizuka I. Ipsilateral dominance of human olfactory activated centers estimated from event-related magnetic fields measured by 122-channel whole head neuromagnetometer using odorant stimuli synchronized with respirations. Ann NY Acad Sci 1998;855 : 579-590

Williamson SI and Kaufman L. Analysis of neuromagnetic signals. In : Gevins AS, Redmond A (Eds): Handbook of electroencephalography and Clinical Neurophysiology, Vol1.Methods and Analysis of Brain Electrical Signals. Elsevier, Amsterdam, 1987.

Wilson TW, Rojas DC, Reite ML, Teale PD, Rogers SJ. Children and adolescents with autism exhibit reduced MEG steady-state gamma responses. Biol Psychiatry. 62(3), 2007, pp.192-197.

Wu JY, Sutherling WW, Koh S, et al. Magnetic source imaging localizes epileptogenic zone in children with tuberous sclerosis complex. Neurology. 66(8), 2006, pp. 1270-1272. 


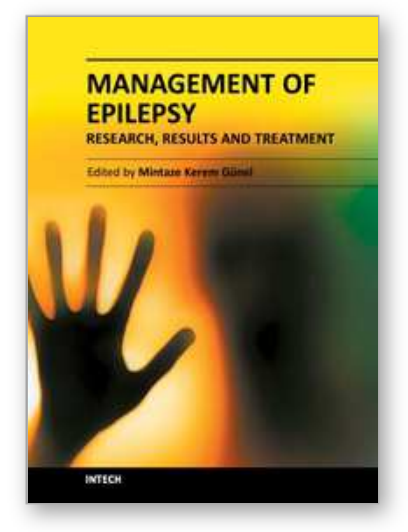

\author{
Management of Epilepsy - Research, Results and Treatment \\ Edited by Prof. Mintaze Kerem GÃ $1 / 4 n e l$
}

ISBN 978-953-307-680-5

Hard cover, 194 pages

Publisher InTech

Published online 15, September, 2011

Published in print edition September, 2011

Epilepsy is one of the most common neurological disorders, with a prevalence of 4-10/1000. The book contains the practical methods to approaching the classification and diagnosis of epilepsy, and provides information on management. Epilepsy is a comprehensive book which guides the reader through all aspects of epilepsy, both practical and academic, covering all aspects of diagnosis and management of children with epilepsy in a clear, concise, and practical fashion. The book is organized so that it can either be read cover to cover for a comprehensive tutorial or be kept desk side as a reference to the epilepsy. Each chapter introduces a number of related epilepsy and its diagnosis, treatment and co-morbidities supported by examples. Included chapters bring together valuable materials in the form of extended clinical knowledge from practice to clinic features.

\title{
How to reference
}

In order to correctly reference this scholarly work, feel free to copy and paste the following:

A. Kotini, A. Tsalkidis, P. Anninos and A. Chatzimichael (2011). The Use of Magnetoencephalography to Evaluate Febrile Seizures and Epilepsy in Children, Management of Epilepsy - Research, Results and Treatment, Prof. Mintaze Kerem GÃ $1 / 4 n e l$ (Ed.), ISBN: 978-953-307-680-5, InTech, Available from: http://www.intechopen.com/books/management-of-epilepsy-research-results-and-treatment/the-use-ofmagnetoencephalography-to-evaluate-febrile-seizures-and-epilepsy-in-children

\section{INTECH}

open science | open minds

\section{InTech Europe}

University Campus STeP Ri

Slavka Krautzeka 83/A

51000 Rijeka, Croatia

Phone: +385 (51) 770447

Fax: +385 (51) 686166

www.intechopen.com

\section{InTech China}

Unit 405, Office Block, Hotel Equatorial Shanghai

No.65, Yan An Road (West), Shanghai, 200040, China 中国上海市延安西路65号上海国际贵都大饭店办公楼 405 单元

Phone: +86-21-62489820

Fax: $+86-21-62489821$ 
(C) 2011 The Author(s). Licensee IntechOpen. This chapter is distributed under the terms of the Creative Commons Attribution-NonCommercialShareAlike-3.0 License, which permits use, distribution and reproduction for non-commercial purposes, provided the original is properly cited and derivative works building on this content are distributed under the same license. 